\title{
Classification and Fractal Characteristics of Limestone Fragments Obtained in Conventional Compression and Cyclic Loading Tests under Uniaxial and Triaxial Conditions
}

\author{
Rui Yang, ${ }^{1,2}$ Xiaodi Wang $\left(\mathbb{D},{ }^{3}\right.$ Hao Zha $\mathbb{D}^{1,2}$ Xiuzhang Yang, ${ }^{4}$ Yang Zhang $\left(\mathbb{D},{ }^{3}\right.$ Gang Huang, ${ }^{3}$ \\ and Yongjie Yang $\mathbb{D}^{3}$ \\ ${ }^{1}$ State Key Laboratory Geomechanics and Deep Underground Engineering, China University of Mining and Technology, Xuzhou, \\ Jiangsu 221116, China \\ ${ }^{2}$ School of Mechanics and Civil Engineering, China University of Mining and Technology, Xuzhou, Jiangsu 221116, China \\ ${ }^{3}$ College of Energy and Mining Engineering, Shandong University of Science and Technology, Qingdao, Shandong 266590, China \\ ${ }^{4}$ College of Civil Engineering and Architecture, Shandong University of Science and Technology, Qingdao, \\ Shandong 266590, China
}

Correspondence should be addressed to Xiaodi Wang; wangxd1103@163.com

Received 16 January 2020; Revised 11 March 2020; Accepted 18 March 2020; Published 24 April 2020

Academic Editor: Luís Evangelista

Copyright (c) 2020 Rui Yang et al. This is an open access article distributed under the Creative Commons Attribution License, which permits unrestricted use, distribution, and reproduction in any medium, provided the original work is properly cited.

\begin{abstract}
The mechanical response characteristics of rocks under cyclic loading conditions are crucial factors for evaluating and analyzing the stability of rock mass during underground excavation. In this study, based on fractal theory and a series of tests using the MTS815.02 rock mechanics test system, the classification and fractal characteristics of limestone specimen fragments are investigated. The results show that limestone specimens subjected to cyclic loading can generate more small-sized fragments than conventional compression, but the large-fragment-producing abilities of the two tests exhibit small difference. The mass fraction of the fragments in the cyclic loading test is obviously greater than that in the conventional test when the fragment size is less than $4.75 \mathrm{~mm}$; however, only a small difference is observed between the cyclic loading tests with frequencies of $0.25 \mathrm{and} 0.5 \mathrm{~Hz}$. In the same type of test, a confining pressure is helpful in reducing the fragmentation of limestone specimen. As the size interval decreases, the shapes of limestone fragment transition from rectangular to long slice and then to square. The results also indicate that the confining pressure has a significant influence on the size-quantity and size-mass fractal dimensions of limestone fragments. The former has a positive correlation with the confining pressure, whereas the latter decreases with confining pressure. The conclusions obtained in this investigation can enrich the theoretical research on the failure response and mechanism of rock under cyclic loading conditions.
\end{abstract}

\section{Introduction}

Mining, tunnel excavation, and other projects in deep mines can involve repeated loading and unloading of rock [1], which has a nonnegligible impact on the strength and longterm stability. Additionally, the fatigue property of rock caused by cyclic loading is an important factor threatening the safety of geotechnical engineering [2-4]. Therefore, investigating the mechanical properties and failure mechanism of rock under cyclic loading conditions is of paramount importance.
At present, the mechanical behavior of rock under cyclic loading tests has been widely studied, and many valuable results have been acquired. Liu and $\mathrm{He}$ [5] conducted triaxial cyclic loading tests at constant amplitude on sandstone specimens. They found that repeated loading and unloading can weaken the rock strength and that the deformation of the specimen can accumulate cycle by cycle. Dilatancy of rock has also been observed during cyclic loading tests [6], and the dilatancy effects are reduced with increasing confining pressure as the compaction mechanism gradually becomes dominant [7]. Additionally, Yang et al. [8] conducted a series 
of multilevel cyclic loading tests on cylindrical coal specimens, and the investigation showed that the peak stress of cyclic loading has a significant effect on the coal specimen fatigue behavior. Meng et al. [9] analyzed the energy evolution and dissipation of sandstone under cyclic loading tests from the initial condition to total failure and revealed the failure mechanism of rock from the viewpoint of energy. From these investigations, the relationship between the strength and deformation of rocks under cyclic loading can be found to be quite different from that under conventional loading. To describe the stress-strain curves of rock under cyclic loading, Liu et al. [10] established a new damage constitutive model based on energy dissipation. The model was well validated by experimental data.

Based on the brief review above, few previous studies have addressed the rock failure response mechanism under repeated loading. Additionally, in the past decade, the use of fractal geometry has been an efficient method for studying rock failure mechanisms $[11,12]$. Fractal geometry is used to describe irregular and disorderly phenomena in nature [13]. It has also been applied in rock mechanics since its establishment [14]. Regarding investigations of the fractal characteristics of rock fragments, certain researchers have performed much research, and numerous significant results have been achieved. To analyze the mechanism of rock burst, Tian et al. [15] conducted a rock burst simulation experiment using granite samples under different loading rates and studied the fractal characteristics of rock fragments. They found that when the rock is under high-loading-rate conditions, the fractal dimension of rock fragments is relatively small, and the rock burst becomes more sudden. To a certain extent, this investigation can explain the failure mechanism during rock burst. Xiao et al. [16] also obtained the failure pattern of coal seams caused by high-pressure water jets based on the fractal characteristics of coal fragments and an image processing method. Furthermore, for rock samples, different loading paths can induce different failure mechanisms and fractal characteristics of fragments [17]. Zhou et al. [18] found that when the strain rate of granite is $10^{0}-10^{2} \mathrm{~s}^{-1}$, the fractal dimension of fragments is approximately $1.2-2.4$, and the value shows a linear relationship with the logarithm of the energy density. Li et al. [19] carried out triaxial loading tests on coal and examined the fractal characteristics of acoustic emissions during the entire process. The conclusion illustrated that different loading steps can induce various damage behaviors. For cyclic loading, based on the research of Li et al. [20], the fractal characteristics of coal fragments increase with the loading rate. This means that when the loading rate is relatively high, the coal is more seriously crushed.

Studies on the mechanical behavior of limestone under cyclic loading tests are rare, and no work revealing the fractal characteristics of limestone fragments generated under cyclic loading conditions has been presented. Therefore, in this study, to fill in this research gap, we conducted a series of conventional compression tests and cyclic loading tests on limestone using the MTS815.02 rock mechanics test system (MTS Systems Corporation, Eden Prairie, MN, USA). Limestone fragments with 9 different pore sizes were sieved and analyzed. Finally, the distributions and fractal characteristics of limestone fragments generated under conventional compression tests and cyclic loading tests with different frequencies were investigated.

\section{Materials and Methods}

2.1. Sample Preparation and Selection. In this study, the blocks of limestone were collected from the immediate roof of the Yangcun Mine No. 10602 coal face in Shandong, China. After these samples were brought back to the laboratory, each sample was processed into several standard cylindrical specimens with a diameter of $50 \mathrm{~mm}$ and a height of $100 \mathrm{~mm}$ by slow drilling, cutting, and polishing. Subsequently, the specimens were measured by an acoustic velocity testing instrument (see Figure 1). The specimens with similar wave velocities were selected for testing. Some specimens are shown in Figure 2.

2.2. Experimental Procedure. Under the uniaxial state and the confining pressure of $10 \mathrm{MPa}$, two types of tests were performed: conventional compression tests and cyclic loading tests. These tests were carried out on the MTS815.02 rock mechanics test system (MTS Systems Corporation, Eden Prairie, MN, USA), as shown in Figure 3.

Prior to each test, an initial force of $1.0 \mathrm{kN}$ was applied to each limestone specimen to ensure that the specimen had close contact with the test machine pressure head. The conventional compression tests were conducted under displacement control mode with a displacement rate of $0.003 \mathrm{~mm} / \mathrm{s}$, aiming at obtaining the strengths of the limestone specimens and providing essential data for the cyclic loading tests. The typical stress-strain diagrams of limestone specimens in conventional compression test are shown in Figure 4. In Figure 4, the symbols $\sigma_{1}, \sigma_{3}$, and $\varepsilon$ represent the axial stress, confining pressure, and strain, respectively. In addition, the stress control mode was employed in the cyclic loading tests. Each specimen was tested for as many as 3,000 cycles with a cosine waveform. The test schemes and results of representative specimens in uniaxial and triaxial conditions are, respectively, shown in Tables 1 and 2. And the corresponding stress-strain diagrams are shown in Figures 5 and 6.

\section{Sieving Test Results and Analysis}

3.1. Sieving Standard. Sieving tests were carried out using four sieves with different pore sizes of $0.6 \mathrm{~mm}, 1.18 \mathrm{~mm}$, $2.0 \mathrm{~mm}$, and $4.75 \mathrm{~mm}$. Subsequently, an electronic balance was adopted for calculating the mass of limestone fragments with different sizes. For fragments larger than $4.75 \mathrm{~mm}$, their three-dimensional sizes were measured by a Vernier caliper. For fragments with sizes less than $4.75 \mathrm{~mm}$, we only obtained the total mass because measuring their three-dimensional size was difficult. In this paper, the limestone fragments were divided into nine grades according to their long axis size. Table 3 lists the classification and measurement procedures for limestone fragments. 


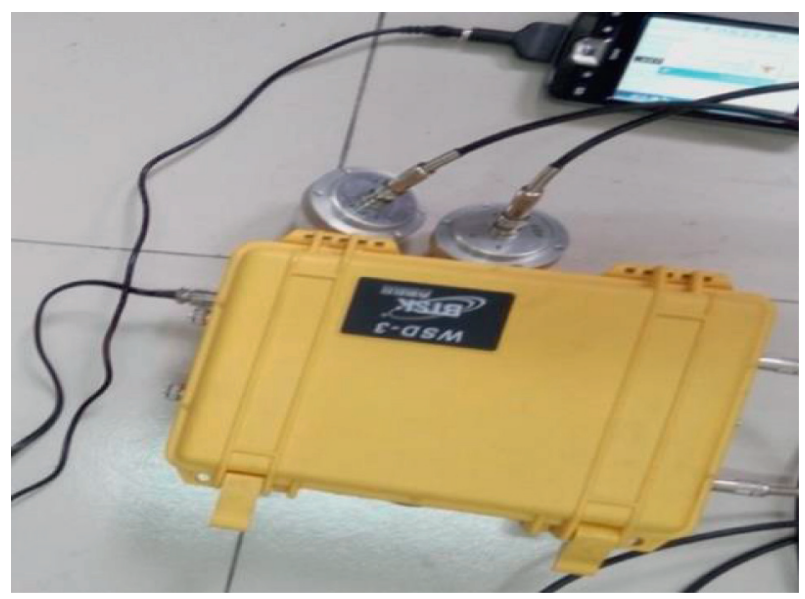

FIgURE 1: Acoustic velocity testing instrument.

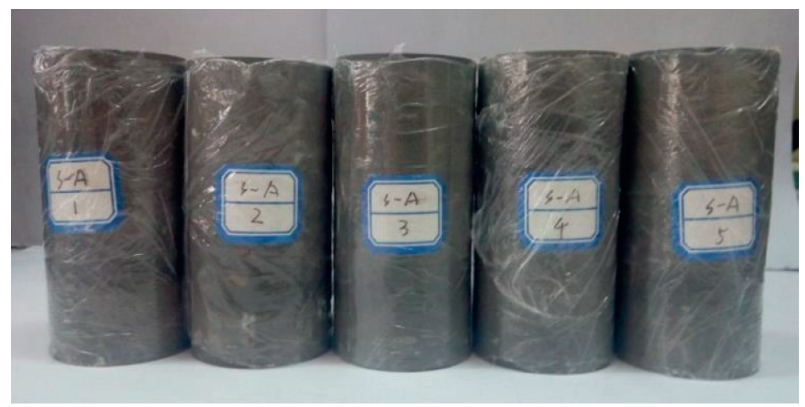

FIGURE 2: Limestone specimens.

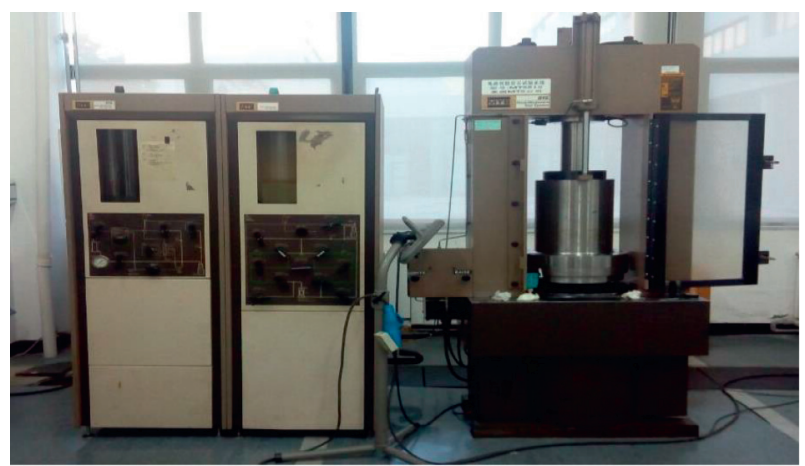

FIGURE 3: MTS815.02 rock mechanics test system.

\subsection{Uniaxial Experimental Results}

3.2.1. Limestone Fragment Classification Characteristics. According to the classification criteria in Table 3, under the uniaxial stress state, the limestone specimen fragments generated in conventional compression and cyclic loading tests were collected. The images of some specimen fragments are shown in Figure 7. The results show that the limestone fragments exhibit an obvious classification feature. The number of fragments generated by conventional compression loading is obviously smaller than that generated by cyclic loading. The phenomenon is more apparent for the small-sized fragments. This means that the damage to limestone under cyclic loading is more severe.

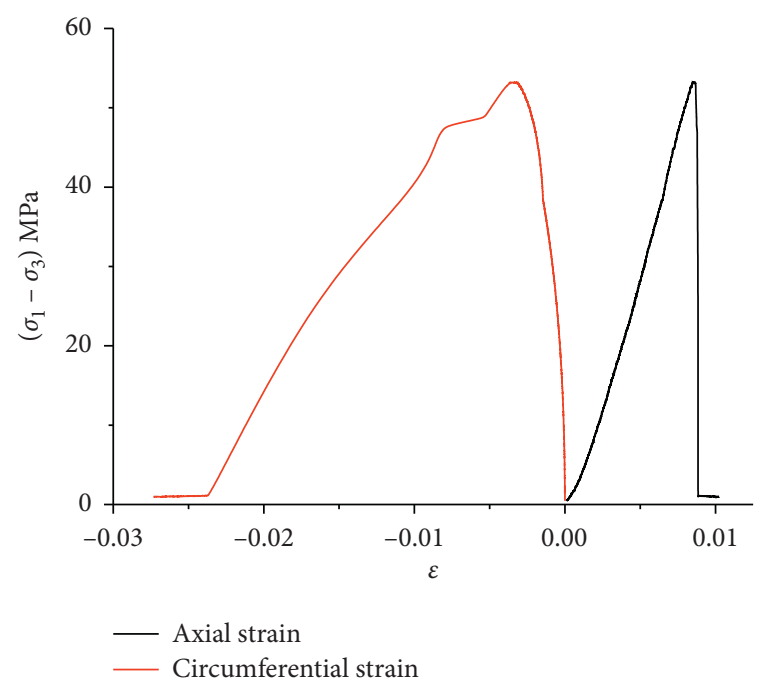

(a)

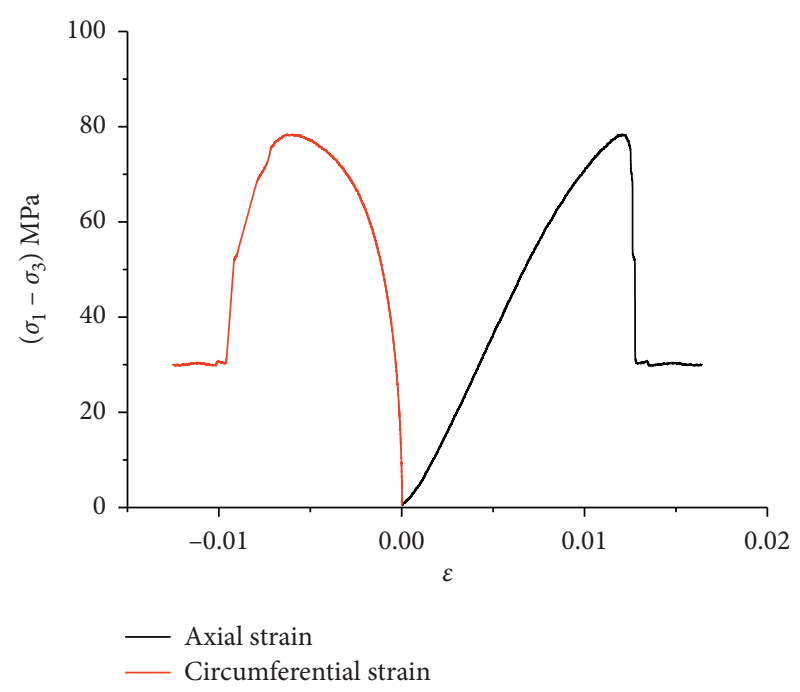

(b)

Figure 4: Stress-strain curves of limestone specimens in the conventional compression test. (a) The uniaxial stress state. (b) The confining pressure of $10 \mathrm{MPa}$.

3.2.2. Limestone Fragment Quantity Characteristics. After sieving the limestone specimen fragments, the number of fragments with length larger than $4.75 \mathrm{~mm}$ was counted according to the test scheme because measuring the size of fragments with length less than $4.75 \mathrm{~mm}$ is very difficult. The statistical results are shown in Table 4. In addition, the number of limestone specimen fragments in different size intervals is shown in Figure 8.

From Figure 8, the following conclusions can be drawn. Under the uniaxial stress state, the number of limestone specimen fragments in all size intervals is greater for the cyclic loading test than for the conventional compression test. In other words, cyclic loading of a limestone specimen is more likely to generate small-sized fragments than conventional compression. Additionally, for fragments with size over $20 \mathrm{~mm}$, the fragment-producing abilities of the cyclic loading test and conventional compression test are almost 
TABLE 1: Test schemes and results of representative specimens subjected to cyclic loading under uniaxial stress state.

\begin{tabular}{lccccc}
\hline Frequency $(\mathrm{Hz})$ & Stress rank & Valley stress level (\%) & Peak stress level (\%) & Cycle number & Failure state \\
\hline \multirow{3}{*}{0.25} & 1 & 30 & 80 & 3000 & Not failed \\
& 2 & 30 & 85 & 3000 & Not failed \\
& 3 & 30 & 90 & 366 & Failed \\
0.5 & 1 & 30 & 80 & 3000 & Not failed \\
& 2 & 30 & 85 & Not failed \\
& 3 & 30 & 90 & 2435 & Failed \\
\hline
\end{tabular}

TABLE 2: Test schemes and results of representative specimens subjected to cyclic loading under the confining pressure of $10 \mathrm{MPa}$.

\begin{tabular}{|c|c|c|c|c|c|}
\hline Frequency $(\mathrm{Hz})$ & Stress rank & Valley stress level (\%) & Peak stress level (\%) & Cycle number & Failure state \\
\hline \multirow{4}{*}{0.25} & 1 & 30 & 80 & 3000 & Not failed \\
\hline & 2 & 30 & 85 & 3000 & Not failed \\
\hline & 3 & 30 & 90 & 3000 & Not failed \\
\hline & 4 & 30 & 92.5 & 425 & Failed \\
\hline \multirow{5}{*}{0.5} & 1 & 30 & 80 & 3000 & Not failed \\
\hline & 2 & 30 & 85 & 3000 & Not failed \\
\hline & 3 & 30 & 90 & 3000 & Not failed \\
\hline & 4 & 30 & 92.5 & 3000 & Not failed \\
\hline & 5 & 30 & 95 & 247 & Failed \\
\hline
\end{tabular}

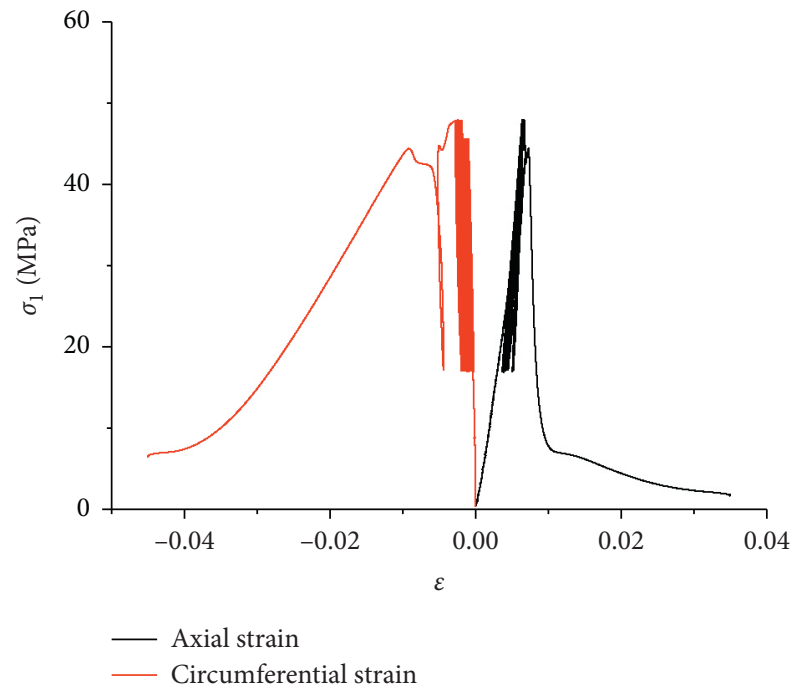

(a)

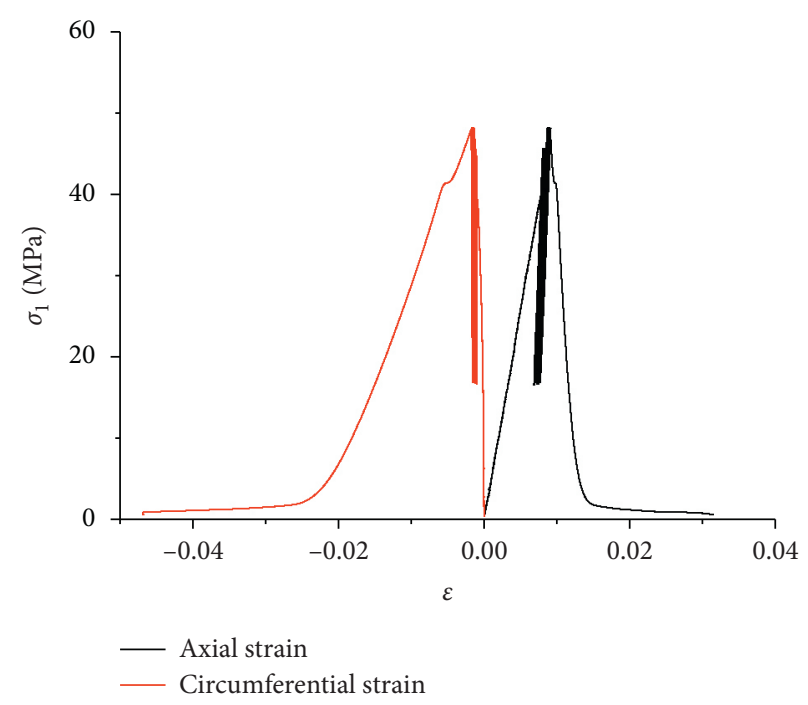

(b)

FIGURE 5: Stress-strain curves of limestone specimens in the uniaxial cyclic loading test. (a) Cyclic loading with a frequency of $0.25 \mathrm{~Hz}$. (b) Cyclic loading with a frequency of $0.5 \mathrm{~Hz}$.

the same because the maximum difference in the number of fragments between the two tests is 3 .

3.2.3. Limestone Fragment Mass Characteristics. The mass fraction of fragments with different sizes obtained under different test conditions is illustrated in Figure 9. This figure shows that, under the uniaxial stress state, the mass fraction of specimen fragments generated in the cyclic loading test is obviously greater than that generated in the conventional compression test when the fragment size is less than $10 \mathrm{~mm}$, and only a small difference is observed between the cyclic loading tests with frequencies of 0.25 and $0.5 \mathrm{~Hz}$. Therefore, the difference in the fragment mass fractions obtained under conventional compression and cyclic loading tests is mainly reflected in the small-sized fragments.

3.2.4. Limestone Fragment Size Distribution Characteristics. After sieving the limestone specimen fragments obtained under different test conditions, we measured the threedimensional sizes of the fragments and calculated the average length, width, and thickness. The results are shown in Figure 10. 


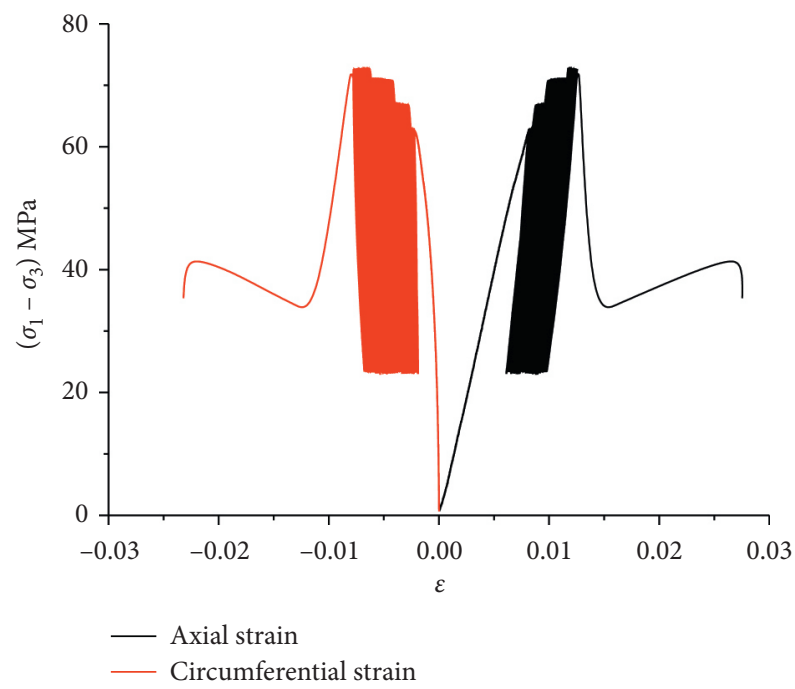

(a)

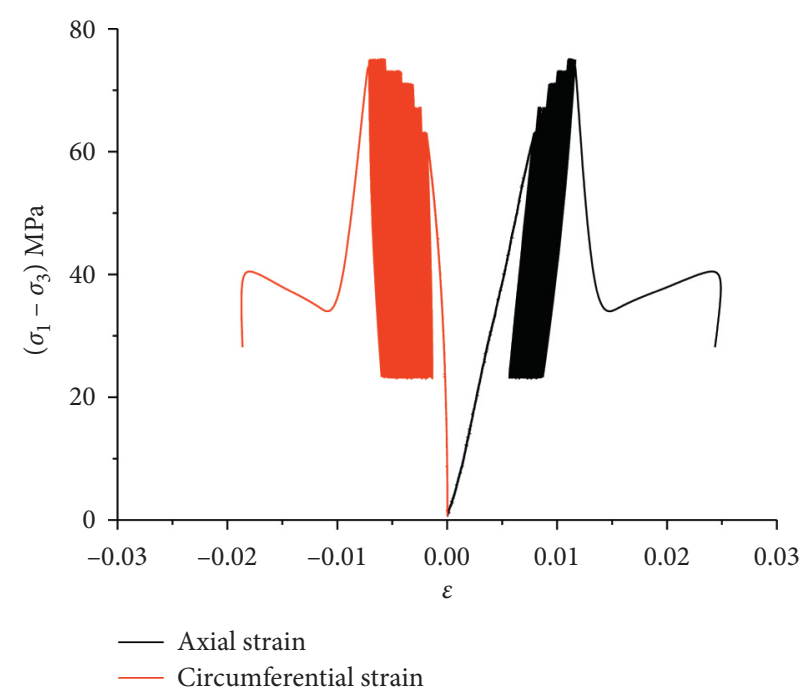

(b)

FiguRE 6: Stress-strain curves of limestone specimens in the triaxial cyclic loading test. (a) Cyclic loading with a frequency of $0.25 \mathrm{~Hz}$. (b) Cyclic loading with a frequency of $0.5 \mathrm{~Hz}$.

TABLE 3: Fragment classification and measurement procedures.

\begin{tabular}{|c|c|c|c|c|}
\hline Number & Category & $\begin{array}{l}\text { Size } \\
(\mathrm{mm})\end{array}$ & Measurement procedures & Goal \\
\hline 1 & Largest-sized fragment & $>50$ & \multirow{5}{*}{$\begin{array}{l}\text { (1) Count the number of fragments } \\
\text { (2) Measure the three-dimensional size of fragments with a } \\
\text { Vernier caliper } \\
\text { (3) Weigh the fragments with an electronic balance }\end{array}$} & \multirow{5}{*}{$\begin{array}{l}\text { (1) Number of } \\
\text { fragments } \\
\text { (2) Size feature } \\
\text { (3) Mass distribution }\end{array}$} \\
\hline 2 & Large-sized fragment & $30 \sim 50$ & & \\
\hline 3 & Medium-sized fragment & $20 \sim 30$ & & \\
\hline 4 & $\begin{array}{c}\text { Medium and small-sized } \\
\text { fragment }\end{array}$ & $10 \sim 20$ & & \\
\hline 5 & Small-sized fragment & $4.75 \sim 10$ & & \\
\hline 6 & Large-sized particle & $2 \sim 4.75$ & \multirow{4}{*}{ Weigh with an electronic balance } & \multirow{4}{*}{ Total mass } \\
\hline 7 & Medium-sized particle & $1.18 \sim 2$ & & \\
\hline 8 & Fine-sized particle & $\begin{array}{c}0.6 \sim \\
1.18\end{array}$ & & \\
\hline 9 & Microsized particle & $<0.6$ & & \\
\hline
\end{tabular}

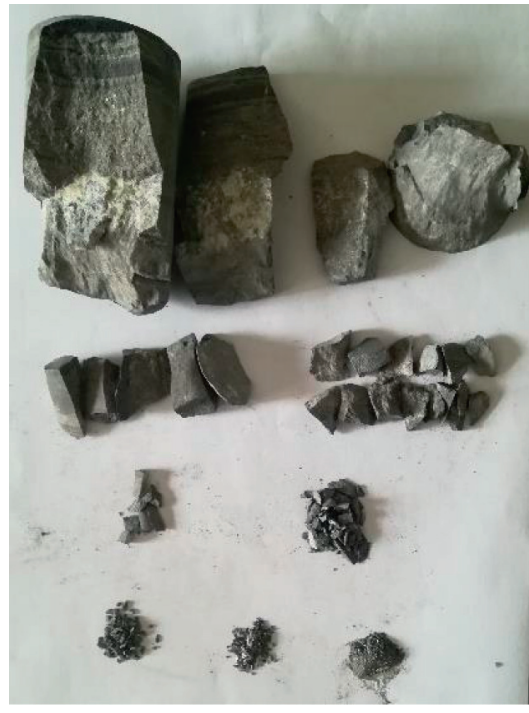

(a)

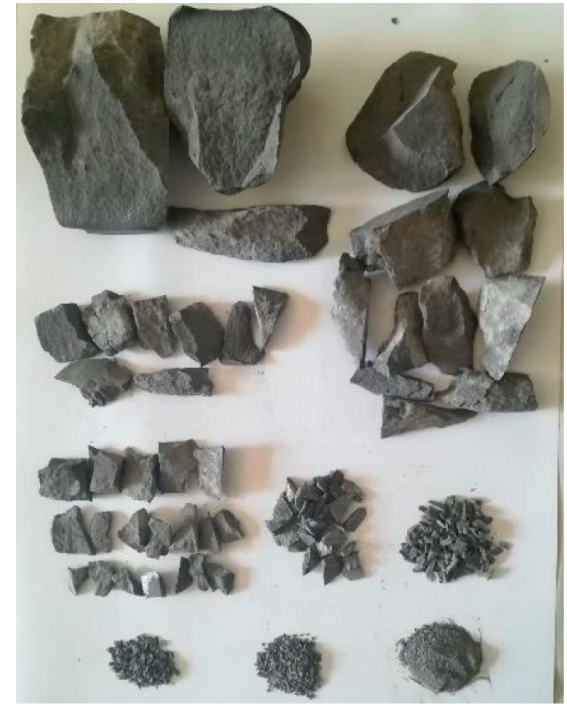

(b)

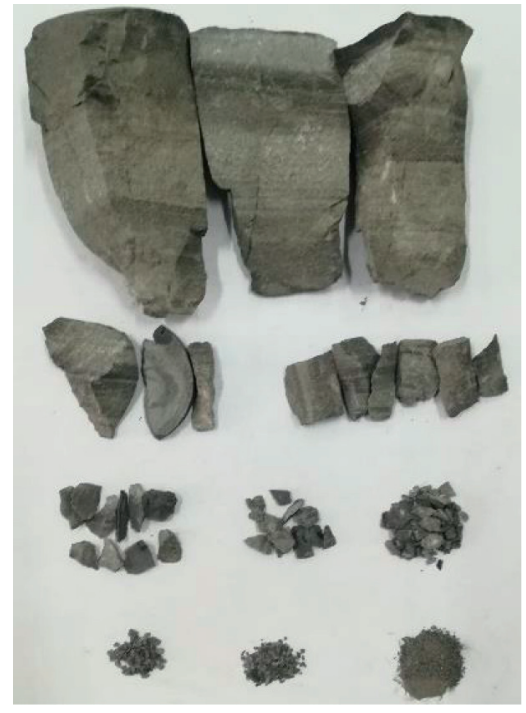

(c)

FIgURE 7: Sieving results of limestone fragments obtained under the uniaxial stress state. (a) Conventional compression test. (b) Cyclic loading test with a frequency of $0.25 \mathrm{~Hz}$. (c) Cyclic loading test with a frequency of $0.5 \mathrm{~Hz}$. 
TABLE 4: Quantity distribution of limestone specimen fragments.

\begin{tabular}{lccc}
\hline Size interval $(\mathrm{mm})$ & Conventional compression & Cyclic loading $(0.25 \mathrm{~Hz})$ & Cyclic loading $(0.5 \mathrm{~Hz})$ \\
\hline$>50$ & 2 & 3 & 3 \\
$30 \sim 50$ & 3 & 5 & 6 \\
$20 \sim 30$ & 4 & 5 & 5 \\
$10 \sim 20$ & 8 & 10 & 10 \\
$4.75 \sim 10$ & 9 & 15 & 13 \\
\hline
\end{tabular}

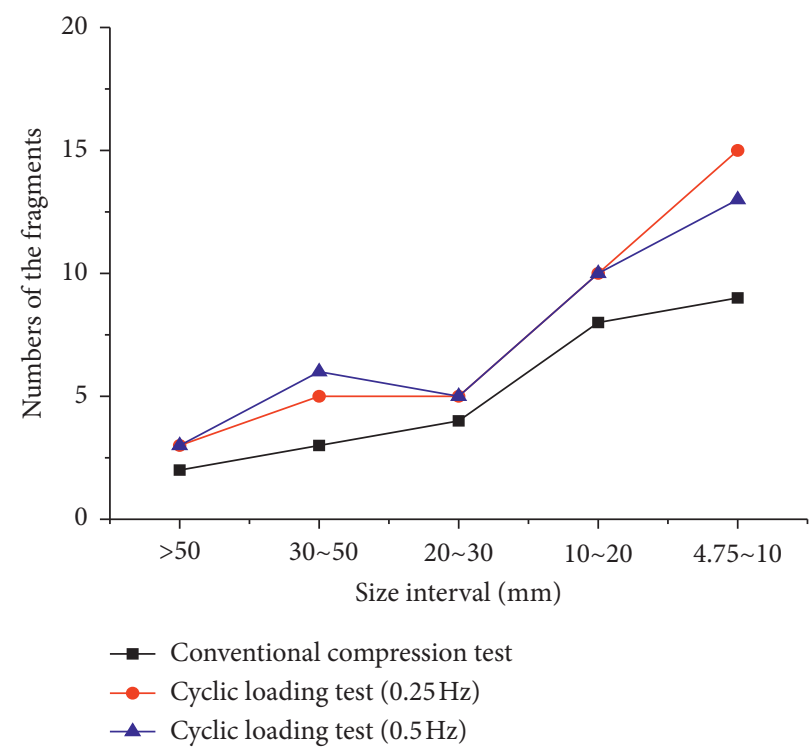

Figure 8: Number of limestone specimen fragments within different size intervals obtained under different test conditions.

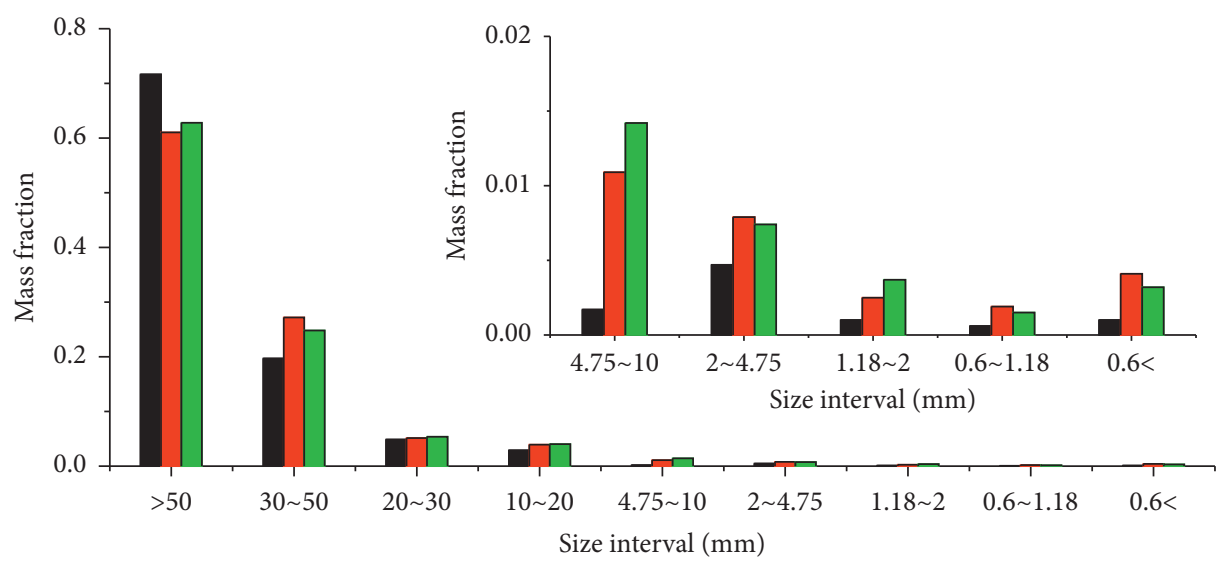

Conventional compression test

$\square$ Cyclic loading test $(0.25 \mathrm{~Hz})$

Cyclic loading test $(0.5 \mathrm{~Hz})$

Figure 9: Mass fraction of limestone specimen fragments in different size intervals obtained under different test conditions.

Clearly, for both the conventional compression test and the cyclic loading test, the "length/width" and "width/ thickness" of limestone fragments are stable with changing size interval. However, the "length/thickness" first increases and then decreases with the fragment size. Thus, most of the large-sized fragments produced in the tests are rectangular, but with decreasing size interval, most fragments are long laminar; additionally, when the size is reduced to the range of $4.75 \mathrm{~mm}$ to $10 \mathrm{~mm}$, the fragment shape gradually transitions to square.

\subsection{Triaxial Experimental Results}

3.3.1. Limestone Fragment Classification Characteristics. According to the classification criteria in Table 3, under the confining pressure of $10 \mathrm{MPa}$, the limestone specimen 


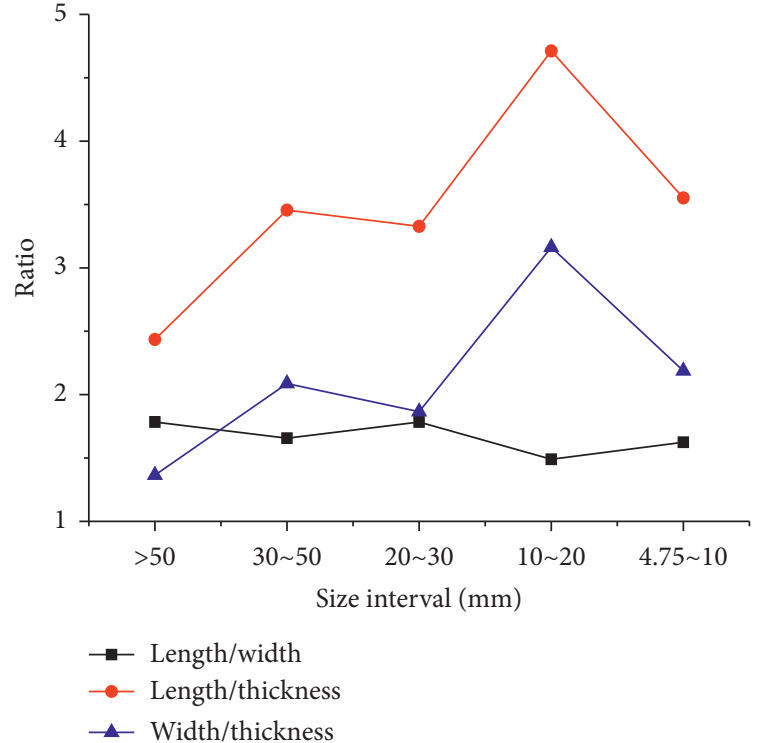

(a)

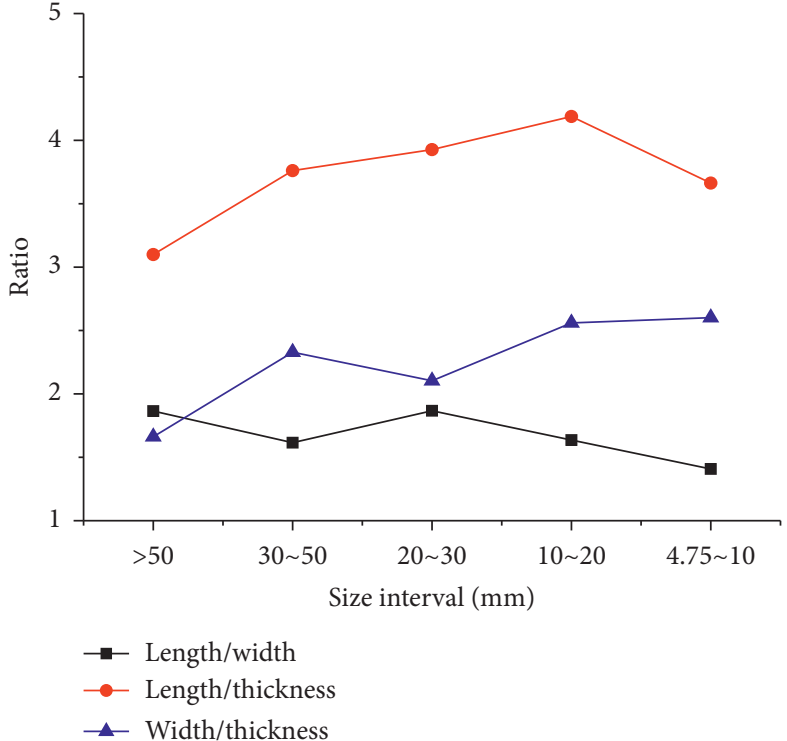

(b)

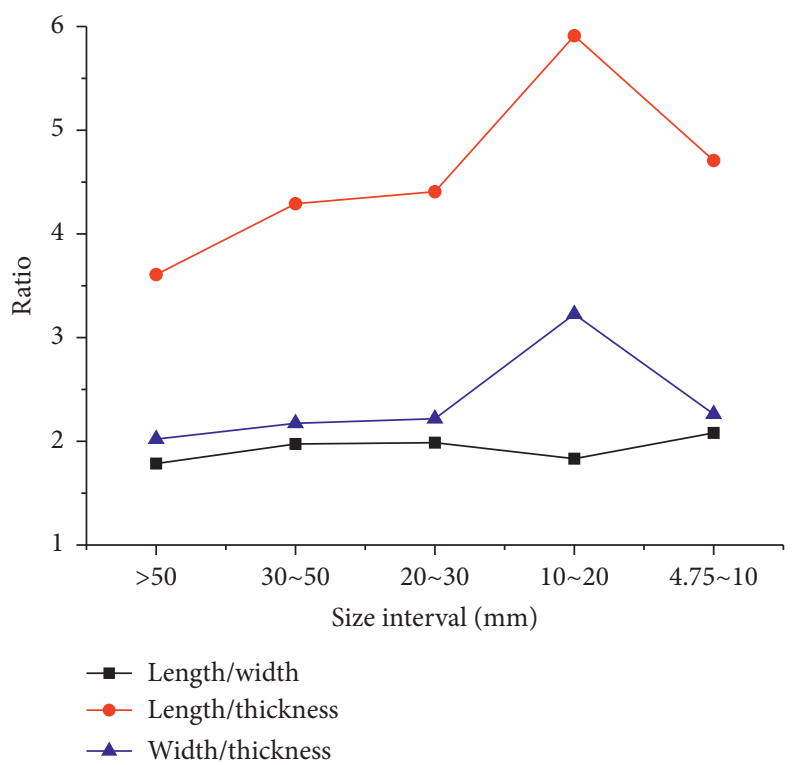

(c)

Figure 10: Size characteristics of limestone specimen fragments obtained under the uniaxial stress state. (a) Conventional compression test. (b) Cyclic loading test with a frequency of $0.25 \mathrm{~Hz}$. (c) Cyclic loading test with a frequency of $0.5 \mathrm{~Hz}$.

fragments generated in conventional compression and cyclic loading tests were collected. The images of some specimen fragments are shown in Figure 11. The results show that the limestone fragments also exhibit obvious classification features. The number of fragments generated by conventional compression loading is smaller than that generated by cyclic loading. The phenomenon is more apparent for the small-sized fragments. This means that the damage to limestone under cyclic loading is more severe.

3.3.2. Limestone Fragment Quantity Characteristics. After sieving the limestone specimen fragments, the number of fragments with length larger than $4.75 \mathrm{~mm}$ was counted according to the test scheme because measuring the size of fragments with length less than $4.75 \mathrm{~mm}$ is very difficult. The statistical results are shown in Table 5. In addition, the number of limestone specimen fragments in different size intervals obtained under different test conditions is shown in Figure 12.

From Figure 12, the following conclusions can be drawn. Under the triaxial stress state, in the range of $4.75 \mathrm{~mm}$ to $20 \mathrm{~mm}$, the number of limestone specimen fragments is greater for the cyclic loading test than for the conventional compression test. In other words, cyclic loading of a limestone specimen is more likely to generate small-sized fragments than conventional compression. Additionally, for fragments with size over $20 \mathrm{~mm}$, the fragment-producing abilities of the 


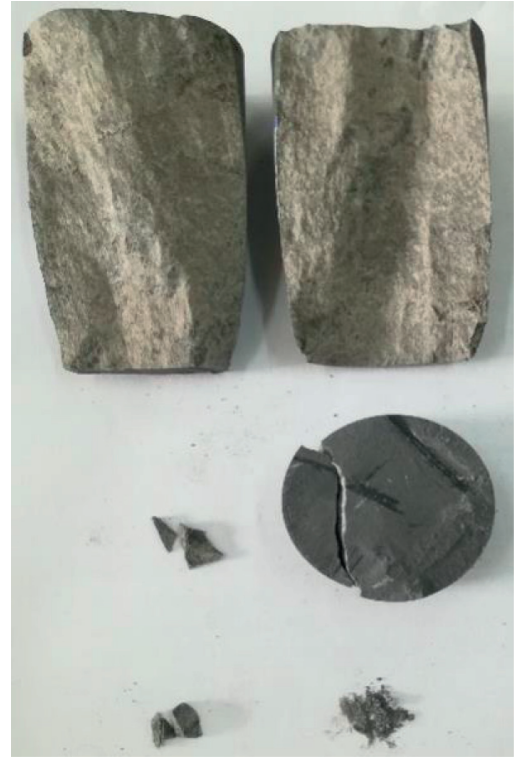

(a)

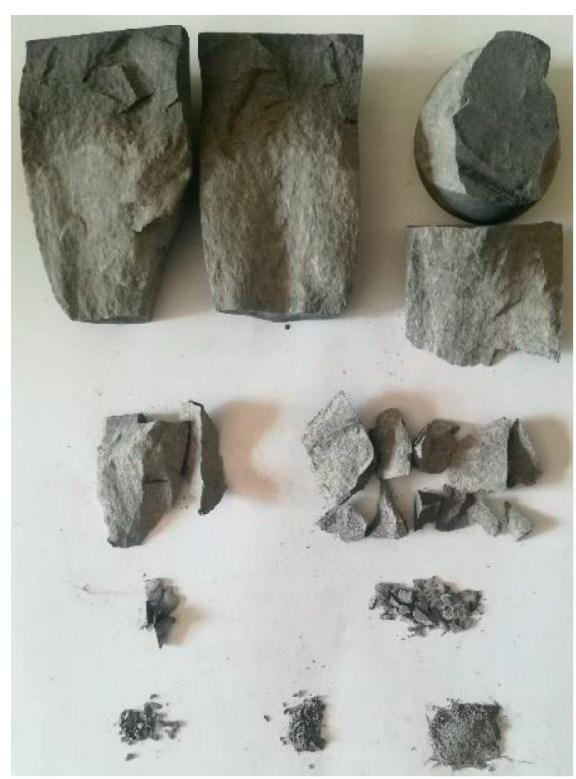

(b)

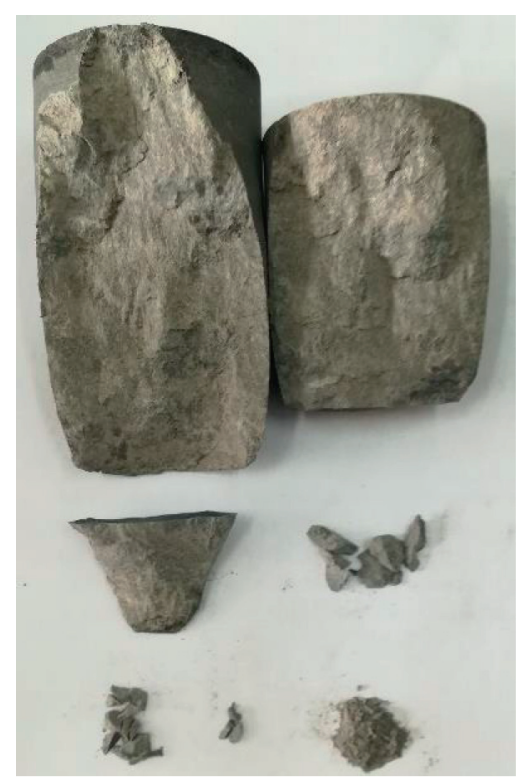

(c)

FIGURE 11: Sieving results of limestone fragments obtained under a confining pressure of $10 \mathrm{MPa}$. (a) Conventional compression test. (b) Cyclic loading test with a frequency of $0.25 \mathrm{~Hz}$. (c) Cyclic loading test with a frequency of $0.5 \mathrm{~Hz}$.

TABLE 5: Quantity distribution of limestone specimen fragments.

\begin{tabular}{lccc}
\hline Size interval $(\mathrm{mm})$ & Conventional compression & Cyclic loading $(0.25 \mathrm{~Hz})$ & Cyclic loading $(0.5 \mathrm{~Hz})$ \\
\hline$>50$ & 2 & 3 & 2 \\
$30 \sim 50$ & 3 & 2 & 1 \\
$20 \sim 30$ & 3 & 2 & 2 \\
$10 \sim 20$ & 3 & 8 & 5 \\
$4.75 \sim 10$ & 8 & 10 & 9 \\
\hline
\end{tabular}

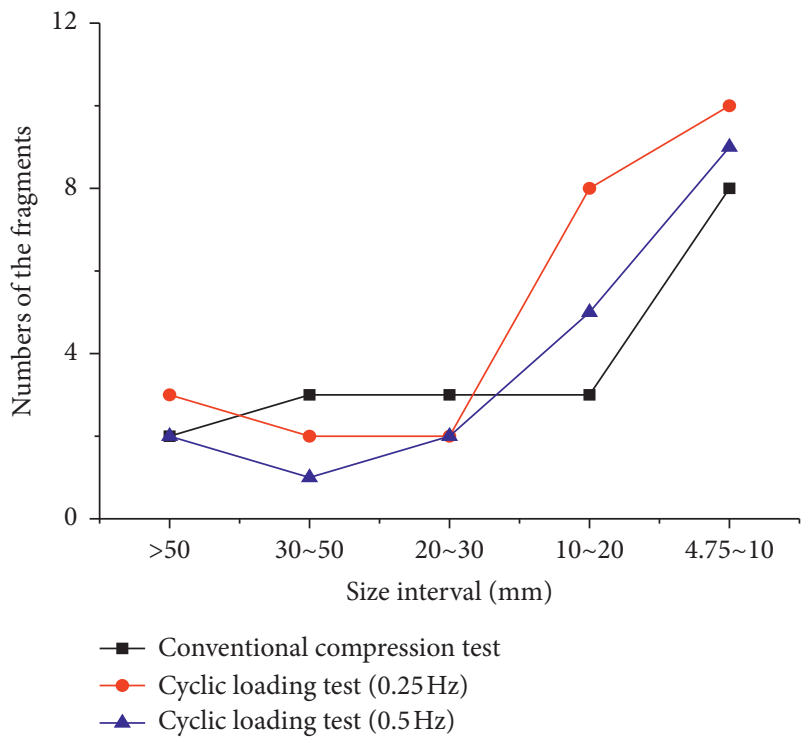

Figure 12: Number of limestone specimen fragments within different size intervals obtained under different test conditions.

cyclic loading test and conventional compression test are almost the same because the maximum difference in the number of fragments between the two tests is 2 .
3.3.3. Limestone Fragment Mass Characteristics. The mass fraction (the proportion of mass of fragments with given size to the total fragments mass) of fragments with different sizes obtained under different test conditions is illustrated in Figure 13. This figure shows that, under the confining pressure of $10 \mathrm{MPa}$, the mass fraction of specimen fragments generated in the cyclic loading test is obviously greater than that generated in the conventional compression test when the fragment size is less than $4.75 \mathrm{~mm}$, and only a small difference is observed between the cyclic loading tests with frequencies of 0.25 and $0.5 \mathrm{~Hz}$. Therefore, the difference in the fragment mass fractions obtained under conventional compression and cyclic loading tests is mainly reflected in the small-sized fragments.

\subsubsection{Limestone Fragment Size Distribution Characteristics.} After sieving the limestone specimen fragments obtained under different test conditions, we measured the three-dimensional sizes of the fragments and calculated the average length, width, and thickness. The results are shown in Figure 14.

Clearly, for both the conventional compression test and the cyclic loading test, the "length/width" and "width/ thickness" of limestone fragments are stable with changing 


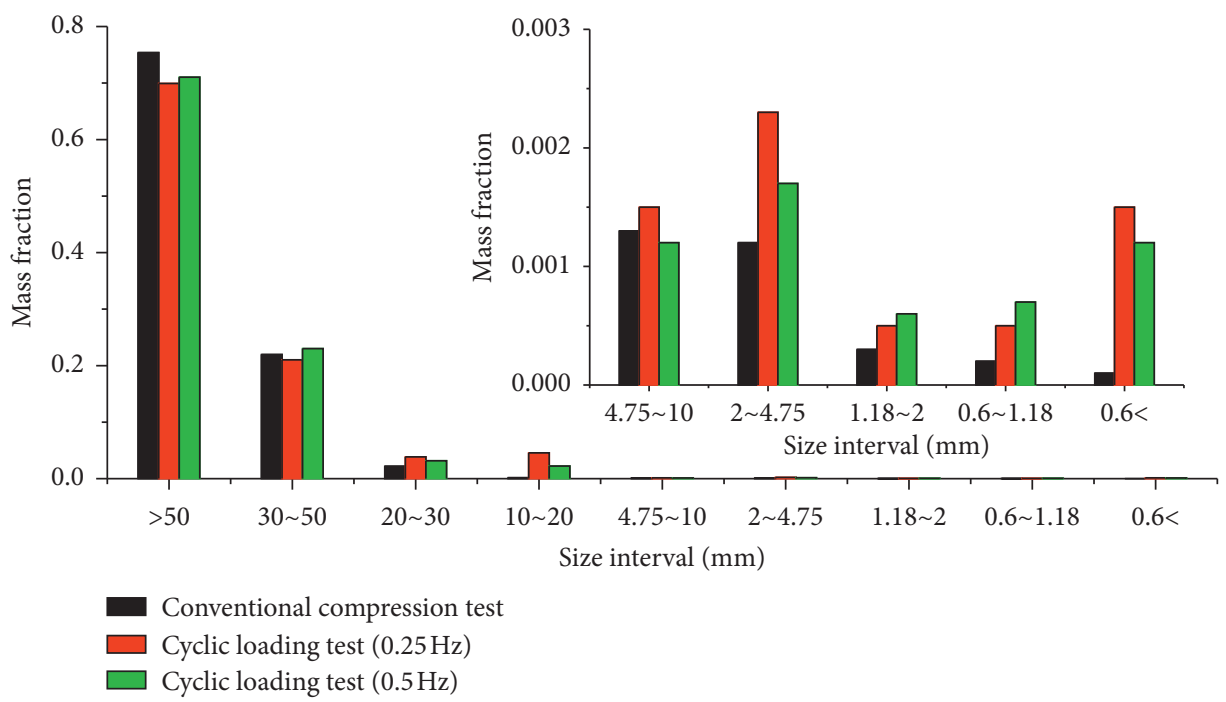

FIGURE 13: Mass fraction of limestone specimen fragments in different size intervals obtained under different test conditions.

size interval. However, the "length/thickness" first increases and then decreases with the fragment size. Thus, most of the large-sized fragments produced in the tests are rectangular, but with decreasing size interval, most fragments are long laminar; additionally, when the size is reduced to the range of $4.75 \mathrm{~mm}$ to $10 \mathrm{~mm}$, the fragment shape gradually transitions to square.

\subsection{Comparison and Analysis of Uniaxial and Triaxial Results.} Compared with the uniaxial stress state, there are obvious differences in quantity characteristics of limestone specimen fragments under the confining pressure of $10 \mathrm{MPa}$ (Figures 8 and 12). Figure 15 shows the differences of limestone fragments in the same type of tests under different confining pressures. Figure 16(a) shows that more fragments are produced in the uniaxial conventional compression test than in the triaxial conventional compression test. However, for the fragment size range of greater than $30 \mathrm{~mm}$, the fragmentproducing abilities are almost the same. Figures 15(b) and 15(c) show that the number of fragments with different sizes produced under the uniaxial condition is greater than that under the triaxial condition in the cyclic loading tests with two different frequencies. Therefore, in the same type of test, a confining pressure can be concluded to be helpful in reducing the fragmentation of limestone specimens. The reason is that the confining pressure can restrict the lateral deformation of limestone specimen, effectively limiting the development of cracks on the surface and inside of limestone specimen, while under uniaxial stress state, the lateral deformation of limestone specimen is free from any restrictions, and it is more broken when it is destroyed.

Compared with the uniaxial stress state, there are obvious differences in mass characteristics of limestone specimen fragments under the confining pressure of $10 \mathrm{MPa}$ (Figures 9 and 13). Figure 16 shows the differences of limestone fragments in the same type of tests under different confining pressures. From Figure 16(a), in the conventional compression test, when the fragment size is greater than $30 \mathrm{~mm}$, the mass fraction of limestone fragments obtained under the confining pressure of $10 \mathrm{MPa}$ is larger than that obtained under the uniaxial stress state. However, when the fragment size is less than $30 \mathrm{~mm}$, the conclusion is the opposite, and the phenomenon is more obvious when the size is less than $4.75 \mathrm{~mm}$. From Figures 16(b) and 16(c) in the cyclic loading tests with frequencies of 0.25 and $0.5 \mathrm{~Hz}$, when the fragment size is greater than $50 \mathrm{~mm}$, the mass fraction of limestone fragments obtained under the confining pressure of $10 \mathrm{MPa}$ is larger than that obtained under the uniaxial stress state. However, when the fragment size is less than $50 \mathrm{~mm}$, the conclusion is the opposite, and the phenomenon is also more obvious when the size is less than $4.75 \mathrm{~mm}$. For both the conventional compression test and the cyclic loading test, the mass fraction of the largest-sized fragments is obviously larger than that of the other size fragments, and this value under a confining pressure is greater than that under uniaxial stress state.

\section{Fractal Characteristics of Limestone Fragments}

4.1. Size-Quantity Fractal Characteristics. To analyze the size-quantity fractal characteristics, we measured the length $(l)$, width $(h)$, and thickness $(w)$ of the fragments with long axis size larger than $4.75 \mathrm{~mm}$, and then, the equivalent length was calculated by the following equation [21]:

$$
L_{\mathrm{eq}}=\sqrt[3]{(l \times h \times w)}
$$

According to previous studies, the fractal dimension can be expressed as follows [22]:

$$
N=N_{0}\left(\frac{L_{\text {eq }}}{L_{\text {eq } \max }}\right)^{-D}
$$

where $N_{0}$ is the number of fragments with the maximum characteristic size of $L_{\text {eq max }} ; D$ is the fractal dimension; and $N$ represents the number of fragments with equivalent length at least $L_{\text {eq }}$. Tables 6 and 7 show, respectively, the number of 


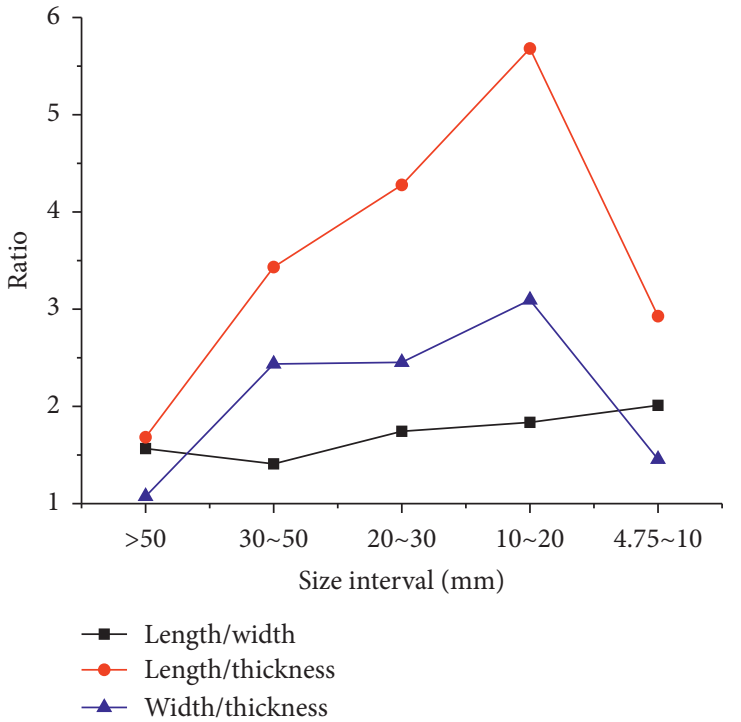

(a)

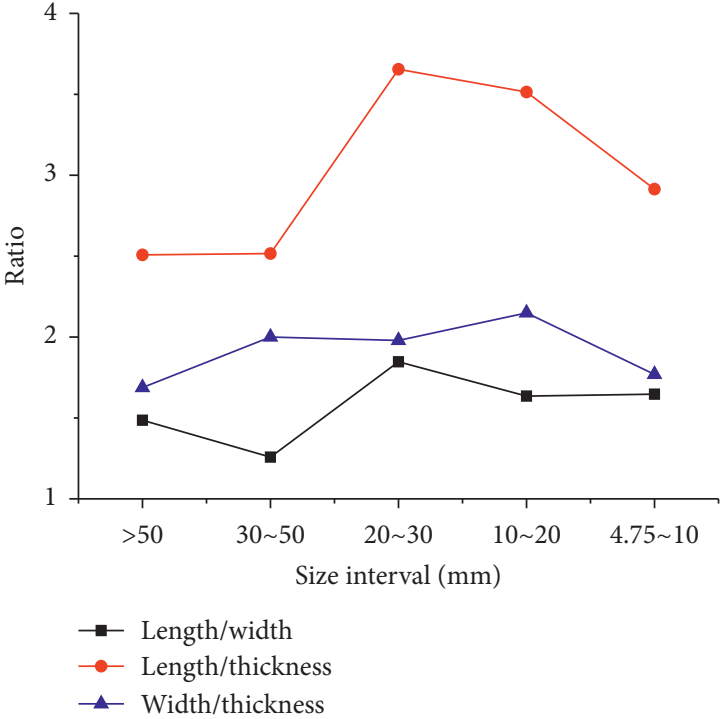

(b)

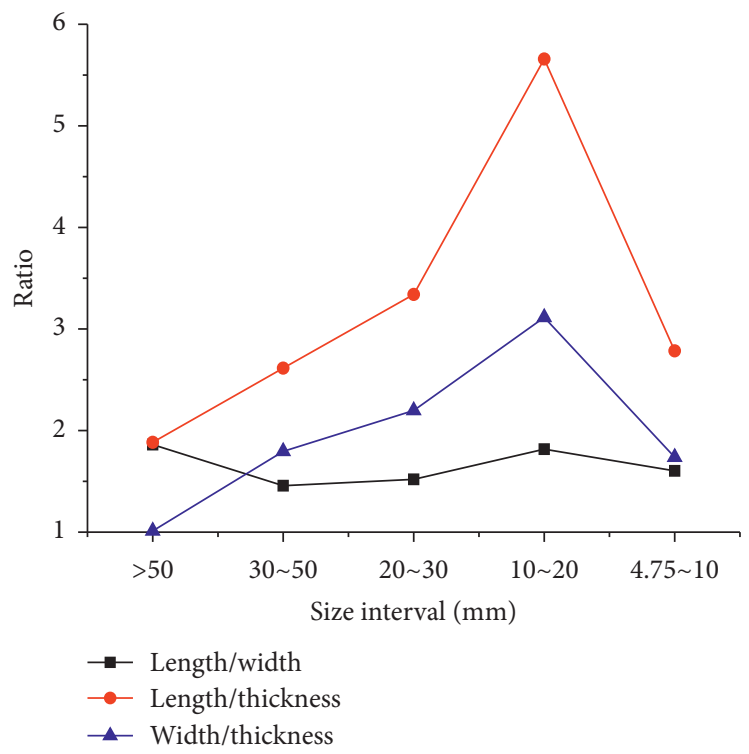

(c)

FIGURE 14: Size characteristics of limestone specimen fragments obtained under the confining pressure of $10 \mathrm{MPa}$. (a) Conventional compression test. (b) Cyclic loading test with a frequency of $0.25 \mathrm{~Hz}$. (c) Cyclic loading test with a frequency of $0.5 \mathrm{~Hz}$.

limestone fragments with different equivalent lengths obtained from different types of test under uniaxial state and the confining pressure of $10 \mathrm{MPa}$. And Figure 17 illustrates the logarithmic plot of the limestone fragment equivalent length-quality under the two confining pressure.

From Figure 17, the following conclusions can be drawn. The linear fitting relationship of $\log (N)-\log \left(L_{\text {eq }}\right)$ is not apparent, and the fractal characteristics are not obvious. However, compared with the uniaxial state, the equivalent length-quantity has a higher fractal dimension under the confining pressure of $10 \mathrm{MPa}$, indicating that the confining pressure has a significant influence on the fractal dimension. This phenomenon occurs because the number of limestone fragments at different scales is very discrete under the uniaxial state. However, under the confining pressure, the number of fragments is restricted, and the number of limestone fragments at different scales is relatively stable.

4.2. Size-Mass Fractal Characteristics. Based on the investigation of Ning et al. [23], the relationship between the number and size can be written as follows:

$$
\frac{M_{\mathrm{Leq}}}{M}=\left(\frac{L_{\mathrm{eq}}}{a}\right)^{\alpha},
$$

where $M$ is the total mass of fragments, $M_{\text {Leq }}$ is the cumulative mass of fragments with equivalent length less than $L_{\mathrm{eq}}$, and $a$ represents the average size of fragments. 


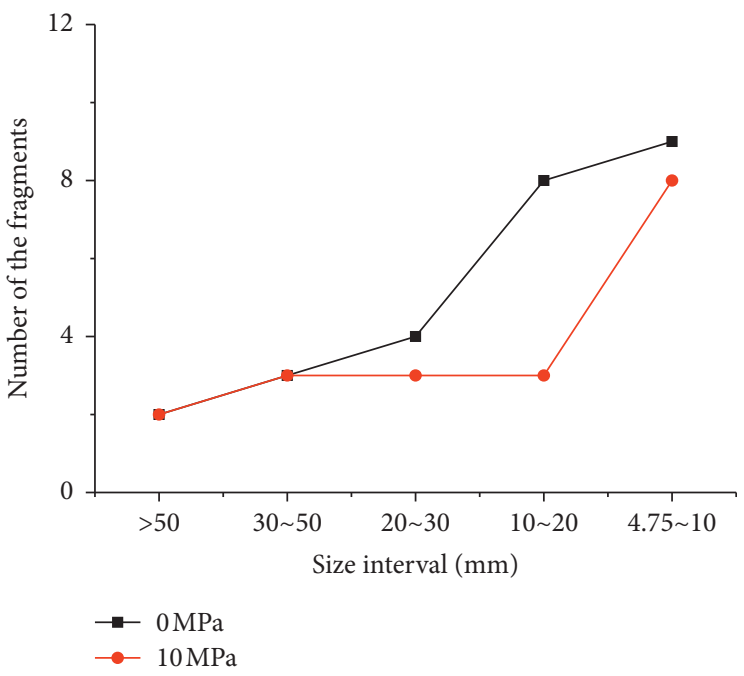

(a)

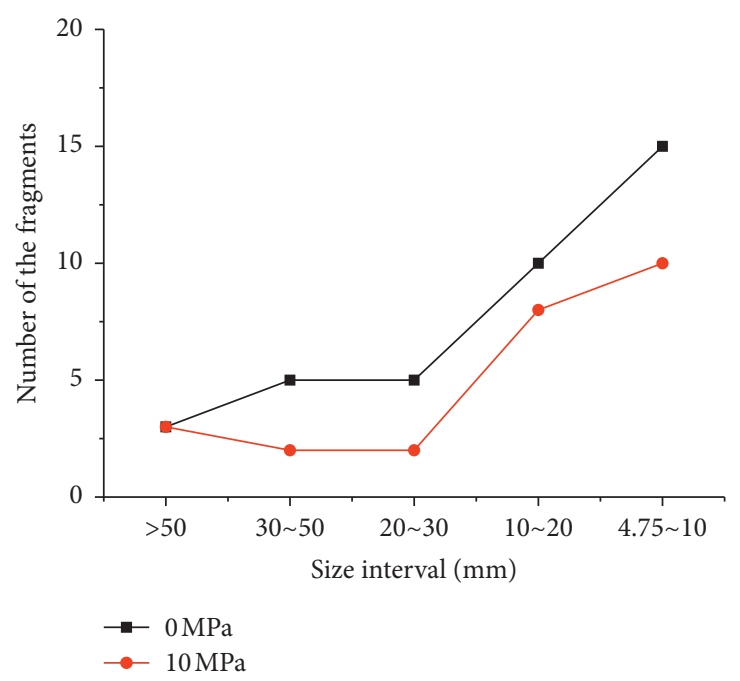

(b)

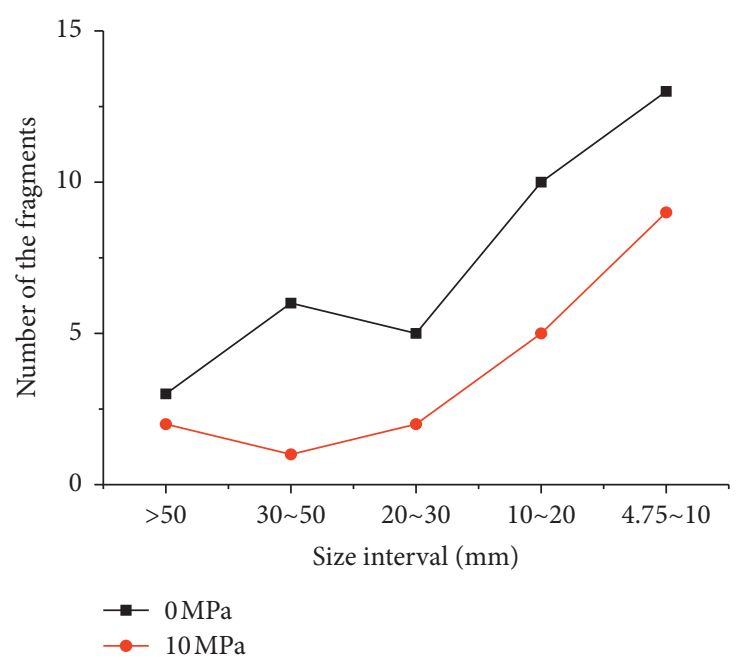

(c)

Figure 15: Number of limestone specimen fragments in different size intervals obtained under different confining pressures. (a) Conventional compression test. (b) Cyclic loading test with a frequency of $0.25 \mathrm{~Hz}$. (c) Cyclic loading test with a frequency of $0.5 \mathrm{~Hz}$.

By taking logarithms on both sides of (3), we can obtain

$$
\lg \left(\frac{M_{\mathrm{Leq}}}{M}\right)=\alpha \lg L_{\mathrm{eq}}-\alpha \lg a,
$$

where $\alpha$ is the slope of the $\lg \left(M_{\text {Leq }} / M\right)-\lg \left(L_{\mathrm{eq}}\right)$ fitting curve. The relationship between the fractal dimension $D$ and $\alpha$ is as follows (the derivation process is shown in Appendix):

$$
D=3-\alpha \text {. }
$$

Tables 8 and 9 show, respectively, the mass of limestone fragments in different equivalent length intervals obtained from different types of test under uniaxial state and the confining pressure of $10 \mathrm{MPa}$. And Figure 18 illustrates the $\lg \left(M_{\mathrm{Leq}} / M\right)-\lg \left(L_{\mathrm{eq}}\right)$ fitting curve for limestone fragments under the two confining pressure. The fractal dimensions are $1.58,1.79,1.76$, and $1.46,1.71,1.74$, respectively.

As displayed in Figure 18, the linear fitting coefficients of the $\lg \left(M_{\mathrm{Leq}} / M\right)-\lg \left(L_{\mathrm{eq}}\right)$ scatter diagrams for both the conventional compression test and the cyclic loading test are over 0.93 under the uniaxial state. This means that the fractal characteristics are obvious. However, under the confining pressure of $10 \mathrm{MPa}$, the values are between 0.82 and 0.90 , and the fractal characteristics are slightly unclear. These results indicate that the confining pressure has a significant influence on the fractal characteristics of limestone fragments, and the fractal characteristics under the uniaxial state are more obvious than those under a confining pressure.

\section{Discussion}

According to the reviewer's comment, we have made some adjustment to the structure of Section 3 and added Section 3.4 for comparison and analysis of uniaxial and triaxial results. Moreover, we added Section 5 for discussion. Section 5 "Discussion" is written as follows. 


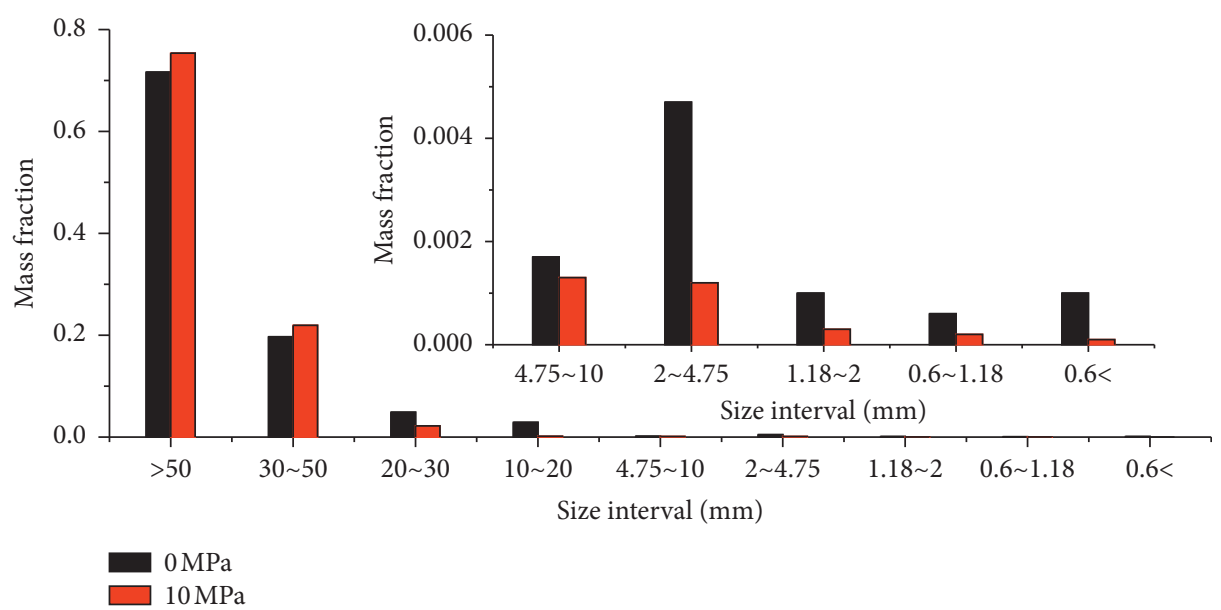

(a)
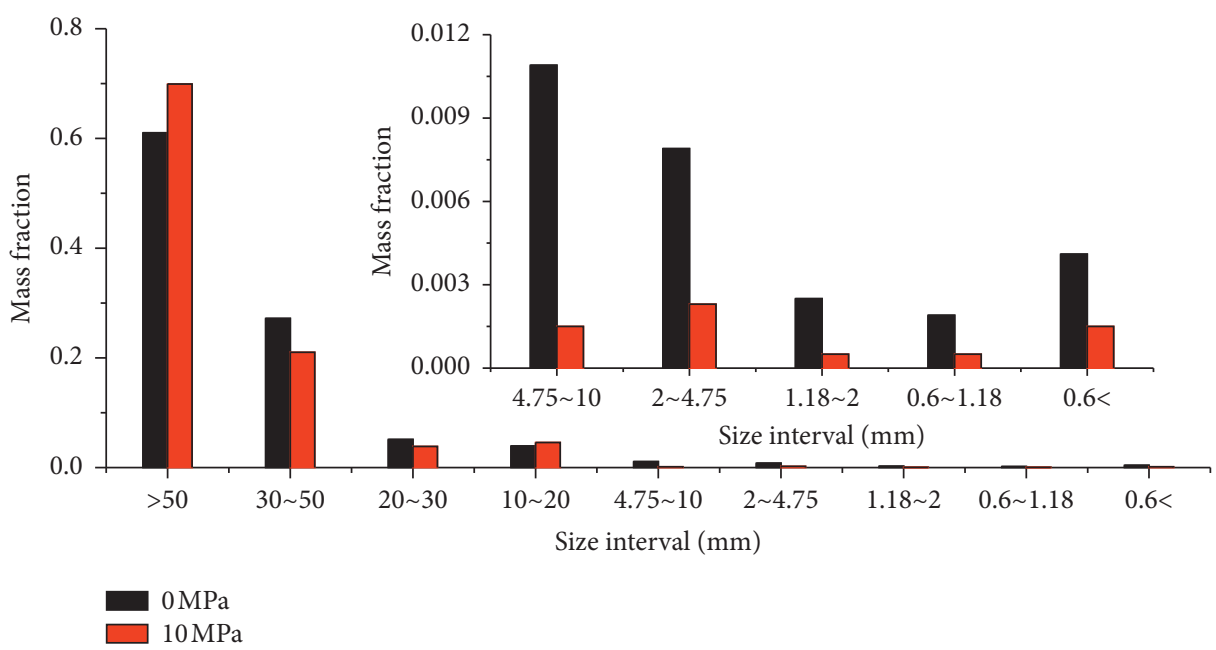

(b)

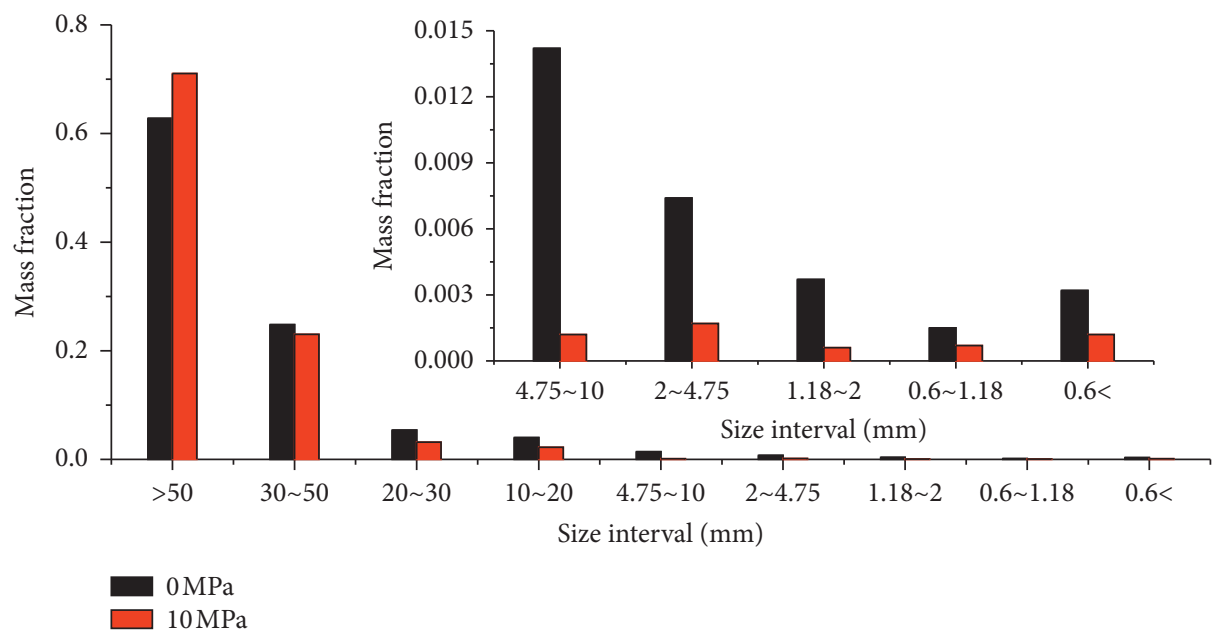

(c)

FIGURE 16: Mass fraction of limestone specimen fragments in different size intervals obtained under different test conditions. (a) Conventional compression test. (b) Cyclic loading test with a frequency of $0.25 \mathrm{~Hz}$. (c) Cyclic loading test with a frequency of $0.5 \mathrm{~Hz}$.

Currently, the mechanical behavior of rock under cyclic loading tests has been widely studied [5-10]. However, there are few achievements on the fractal characteristics of rock fragments $[16,20,23]$. Based on the current insufficient research situation, the main objective of this paper is to reveal the classification and fractal characteristics of broken 
TABLE 6: Equivalent length interval and quantity under the uniaxial stress state.

\begin{tabular}{lccc}
\hline Equivalent length interval $(\mathrm{mm})$ & \multicolumn{2}{c}{$\begin{array}{c}\text { Number } \\
\text { Conventional compression test }\end{array}$} & $\begin{array}{c}\text { Cyclic loading test }(0.25 \mathrm{~Hz}) \\
\text { Cyclic loading test }(0.25 \mathrm{~Hz})\end{array}$ \\
\hline $35 \sim 65$ & 3 & 3 & 3 \\
$20 \sim 35$ & 1 & 6 & 1 \\
$10 \sim 20$ & 10 & 19 & 7 \\
$4.75 \sim 10$ & 11 & 36 & 21 \\
\hline
\end{tabular}

TABLE 7: Equivalent length interval and quantity under the confining pressure of $10 \mathrm{MPa}$.

\begin{tabular}{lccc}
\hline Equivalent length interval $(\mathrm{mm})$ & \multicolumn{2}{c}{$\begin{array}{c}\text { Number } \\
\text { Conventional compression test }\end{array}$} & $\begin{array}{c}\text { Cyclic loading test }(0.25 \mathrm{~Hz}) \\
\text { Cyclic loading test }(0.25 \mathrm{~Hz})\end{array}$ \\
\hline $35 \sim 65$ & 3 & 4 & 2 \\
$20 \sim 35$ & 1 & 1 & 1 \\
$10 \sim 20$ & 2 & 7 & 3 \\
$4.75 \sim 10$ & 2 & 8 & 5 \\
\hline
\end{tabular}

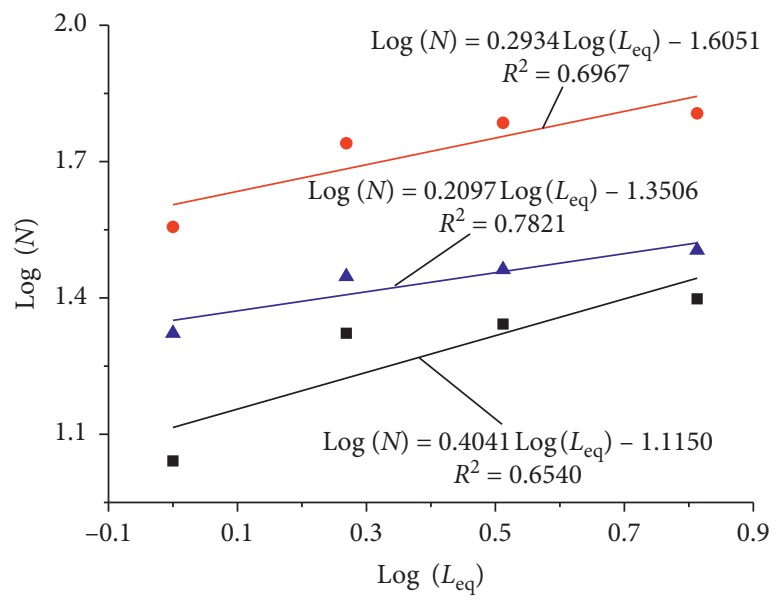

- Conventional compression test

- Cyclic loading test $(0.25 \mathrm{~Hz})$

- Cyclic loading test $(0.5 \mathrm{~Hz})$

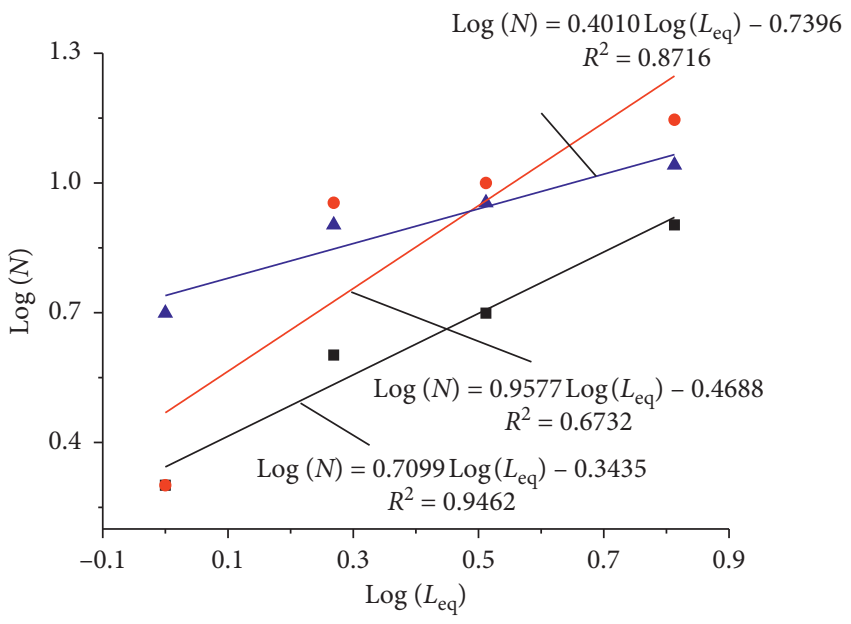

- Conventional compression test

- Cyclic loading test $(0.25 \mathrm{~Hz})$

A Cyclic loading test $(0.5 \mathrm{~Hz})$

(a)

(b)

FIGURE 17: Logarithmic plot of limestone fragment equivalent length-quantity. (a) Uniaxial stress state. (b) Confining pressure of 10 MPa.

TABLE 8: Equivalent length interval and mass of limestone fragments under the uniaxial stress state.

\begin{tabular}{lccc}
\hline Equivalent length interval $(\mathrm{mm})$ & \multicolumn{2}{c}{$\begin{array}{c}\text { Number } \\
\text { Conventional compression test }\end{array}$} & $\begin{array}{c}\text { Cyclic loading test }(0.25 \mathrm{~Hz}) \\
\text { Cyclic loading test }(0.25 \mathrm{~Hz})\end{array}$ \\
\hline $35 \sim 65$ & 412.58 & 285.51 & 397.95 \\
$20 \sim 35$ & 19.35 & 103.08 & 9.98 \\
$10 \sim 20$ & 30.62 & 63.73 & 23.89 \\
$4.75 \sim 10$ & 6.17 & 11.598 & 6.479 \\
$2 \sim 4.75$ & 2.91 & 5.292 & 3.191 \\
$1.18 \sim 2$ & 0.45 & 0.96 & 0.45 \\
$0.6 \sim 1.18$ & 0.27 & 0.91 & 0.37 \\
$<0.6$ & 0.47 & 1.95 & 0.87 \\
\hline
\end{tabular}

fragments of limestone specimens subjected to the conventional compression and cyclic loading by experimental tests. Under both the uniaxial stress state and the confining pressure of $10 \mathrm{MPa}$, the number of limestone specimen fragments generated in the cyclic loading test is greater than that generated in the conventional compression test; and the mass fraction of the fragments in the former test is obviously greater than that in the latter test when the fragment size is 
TABLE 9: Equivalent length interval and mass of limestone fragments under the confining pressure of $10 \mathrm{MPa}$.

\begin{tabular}{lccc}
\hline Equivalent length interval $(\mathrm{mm})$ & \multicolumn{2}{c}{$\begin{array}{c}\text { Number } \\
\text { Conventional compression test }\end{array}$} & $\begin{array}{c}\text { Cyclic loading test }(0.25 \mathrm{~Hz}) \\
\text { Cyclic loading test }(0.25 \mathrm{~Hz})\end{array}$ \\
\hline $35 \sim 65$ & 469.79 & 385.93 & 442.51 \\
$20 \sim 35$ & 10.89 & 12.97 & 14.75 \\
$10 \sim 20$ & 2.47 & 20.27 & 4.87 \\
$4.75 \sim 10$ & 0.87 & 2.96 & 1.65 \\
$2 \sim 4.75$ & 0.27 & 1.14 & 1.08 \\
$1.18 \sim 2$ & 0.09 & 0.23 & 0.11 \\
$0.6 \sim 1.18$ & 0.08 & 0.23 & 0.23 \\
$<0.6$ & 0.11 & 0.65 & 0.49 \\
\hline
\end{tabular}

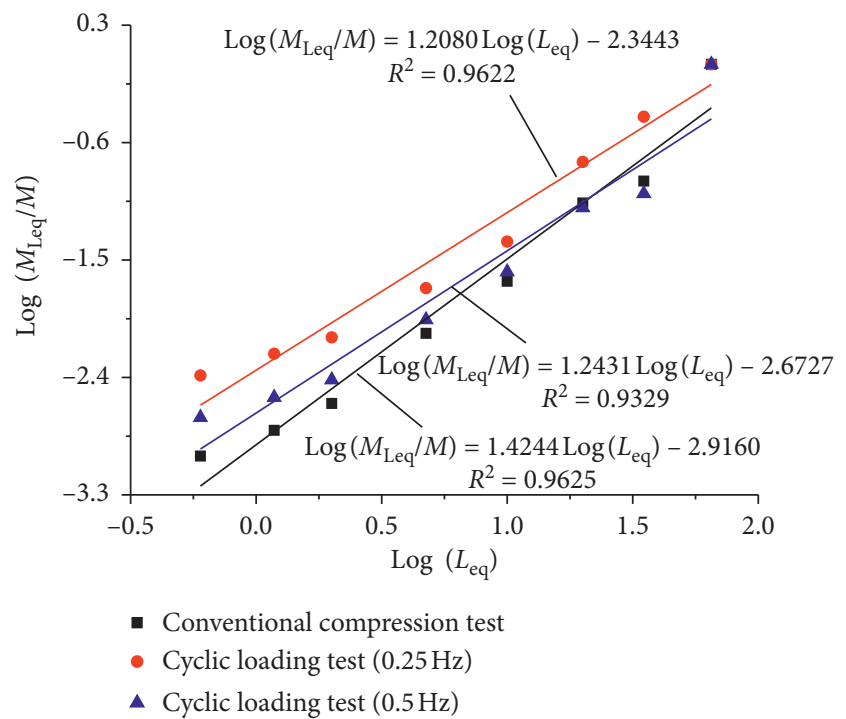

(a)

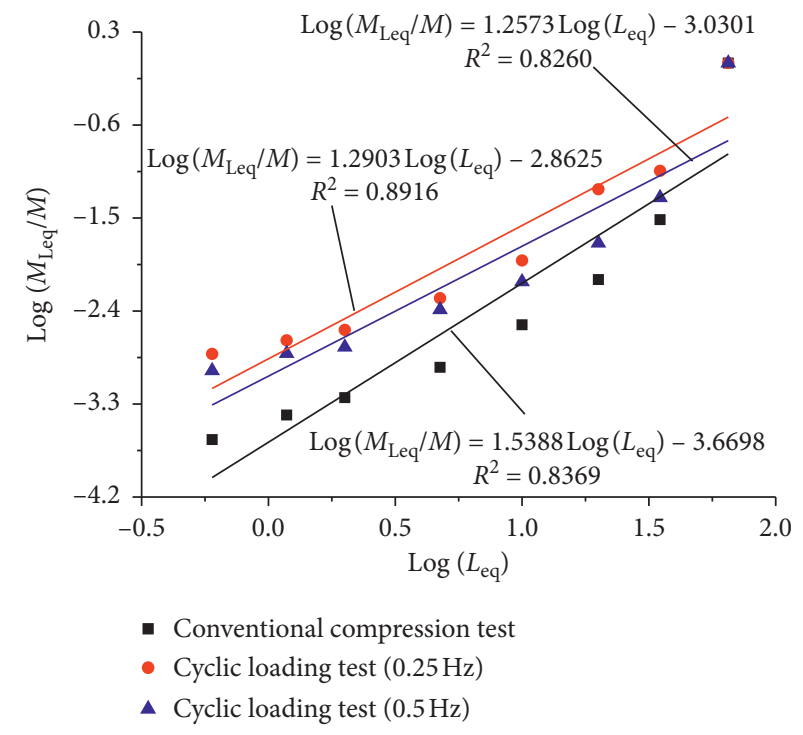

(b)

FIGURE 18: Logarithmic plot of the limestone fragment equivalent length-weight. (a) Uniaxial stress state. (b) Confining pressure of 10 MPa.

less than $4.75 \mathrm{~mm}$. However, only a small difference is observed between the cyclic loading tests with frequencies of 0.25 and $0.5 \mathrm{~Hz}$. Additionally, in the same type of test, a confining pressure is helpful in reducing the fragmentation of limestone specimen. Of course, in this paper, only the conventional compression tests with two confining pressures and only the cyclic loading tests with two frequencies under two confining pressures are carried out; thus, the classification and fractal characteristics of limestone fragments with changing of the confining pressure or frequency cannot be determined completely. We speculate that, in the same type of test, the different loading time may lead to the different classification and fractal characteristics of limestone specimen fragments. These problems will be further studied in the next work. In particular, it is more practical to study these characteristics of the rock assemblages.

The classification and fractal characteristics of limestone specimen fragments are related to the confining pressure and loading type, etc. Therefore, through the in-situ geological detection and experimental test results of the classification and fractal characteristics of the actual rock mass fragments, the type of loading that triggered the collapse of rock mass can be observed, and the targeted supporting measures can be adopted to protect the engineering rock mass. For the engineering rock mass that collapsed by static loading, the basic supporting strength should be improved, while for the engineering rock mass damaged by dynamic loading or impact loading, in addition to the measures mentioned above, some other measures preventing shock and vibration also should be used at the same time.

\section{Conclusions}

In this paper, the classification and fractal characteristics of limestone fragments generated under the conventional compression and cyclic loading are studied. The main conclusions are as follows:

(1) Under both the uniaxial stress state and the confining pressure of $10 \mathrm{MPa}$, the number of limestone specimen fragments generated in the cyclic loading test is greater than that generated in the conventional compression test; and the mass fraction of the fragments in the former test is obviously greater than that in the latter test when the fragment size is less than $4.75 \mathrm{~mm}$; however, only a small difference is 
observed between the cyclic loading tests with frequencies of 0.25 and $0.5 \mathrm{~Hz}$.

(2) In the same type of test, a confining pressure is helpful in reducing the fragmentation of limestone specimen. The reason is that the confining pressure can restrict the lateral deformation of limestone specimen, effectively limiting the development of cracks on the surface and inside of limestone specimen, while under uniaxial stress state, the lateral deformation of limestone specimen is free from any restrictions, and it is more broken when it is destroyed.

(3) Most of the large-sized fragments produced in the tests are rectangular; with decreasing size interval, most fragments are long laminar, and when the size is reduced to the range of $4.75 \mathrm{~mm}$ to $10 \mathrm{~mm}$, the fragment shape gradually transitions to square.

(4) The confining pressure has a significant influence on the size-quantity and size-mass fractal dimensions of the limestone fragments, but the effects are the opposite. Under a confining pressure, the sizequantity fractal dimension tends to increase, whereas the size-mass fractal dimension of the size-mass tends to decrease.

(5) In order to evaluate the stability of rock mass with the fractal theory, the relationship between the evolution of surface cracks in rock mass and fractal dimension should be studied. If the fractal characteristic values at several key points of rock mass from stability to failure can be determined, then we can use the fractal theory to evaluate the stability of engineering rock mass. It also should be noted that the accuracy of rock mass stability evaluation is based on the statistics and analysis of considerable engineering rock fractal data.

\section{Appendix}

The derivation process of (5):

By differentiating (2) and (3), we obtained

$$
\begin{gathered}
\mathrm{d} N \propto L_{\text {eq }}^{-D-1} \mathrm{~d} L_{\text {eq }}, \\
\mathrm{d} M_{\text {Leq }} \propto L_{\text {eq }}^{\alpha-1} \mathrm{~d} L_{\text {eq }} .
\end{gathered}
$$

Considering that the densities of all fragments are the same, the following can be derived:

$$
\mathrm{d} M_{\text {Leq }} \propto L_{\text {eq }}^{3} \mathrm{~d} N \text {. }
$$

Combining (A.1)-(A.3), the relationship between $D$ and $\alpha$ is yielded:

$$
D=3-\alpha
$$

\section{Data Availability}

The data used to support the findings of this study are available from the corresponding author upon request.

\section{Conflicts of Interest}

The authors declare that there are no conflicts of interest regarding the publication of this paper.

\section{Acknowledgments}

This study was supported by the National Key R\&D Program of China (2018YFC0604705).

\section{References}

[1] B. Cerfontaine and F. Collin, "Cyclic and fatigue behavior of rock materials: review, interpretation and research perspectives," Rock Mechanics and Rock Engineering, vol. 51, no. 2, pp. 391-414, 2018.

[2] G. F. Wang, S. Y. Gong, Z. L. Li, L. M. Dou, W. Cai, and Y. Mao, "Evolution of stress concentration and energy release before rock bursts: two case studies from Xingan coal mine, Hegang, China," Rock Mechanics and Rock Engineering, vol. 49, no. 8, pp. 3393-3401, 2016.

[3] M. B. Wold, L. D. Connell, and S. K. Choi, "The role of spatial variability in coal seam parameters on gas outburst behaviour during coal mining," International Journal of Coal Geology, vol. 75, no. 1, pp. 1-14, 2008.

[4] Q. A. Wu, Y. Z. Liu, and L. Yang, "Using the vulnerable index method to assess the likelihood of a water inrush through the floor of a multi-seam coal mine in China," Mine Water and the Environment, vol. 30, no. 1, pp. 54-60, 2011.

[5] E. L. Liu and S. M. He, "Effects of cyclic dynamic loading on the mechanical properties of intact rock samples under confining pressure conditions," Engineering Geology, vol. 125, pp. 81-91, 2012.

[6] N. Gatelier, F. Pellet, and B. Loret, "Mechanical damage of an anisotropic porous rock in cyclic triaxial tests," International Journal of Rock Mechanics and Mining Sciences, vol. 39, no. 3, pp. 335-354, 2002.

[7] M. J. Heap and D. R. Faulkner, "Quantifying the evolution of static elastic properties as crystalline rock approaches failure," International Journal of Rock Mechanics and Mining Sciences, vol. 45, no. 4, pp. 564-573, 2008.

[8] Y. J. Yang, H. Q. Duan, L. Y. Xing, and L. Deng, "Fatigue characteristics of coal specimens under cyclic uniaxial loading," Geotechnical Testing Journal, vol. 42, no. 2, pp. 331-346, 2019.

[9] Q. B. Meng, M. W. Zhang, L. J. Han, H. Pu, and T. Y. Nie, "Effects of acoustic emission and energy evolution of rock specimens under the uniaxial cyclic loading and unloading compression," Rock Mechanics and Rock Engineering, vol. 49, no. 10, pp. 3873-3886, 2016.

[10] X. S. Liu, J. G. Ning, Y. L. Tan, and Q. H. Gu, "Damage constitutive model based on energy dissipation for intact rock subjected to cyclic loading," International Journal of Rock Mechanics and Mining Sciences, vol. 85, pp. 27-32, 2016.

[11] T. X. Hou, Q. Xu, and J. W. Zhou, "Size distribution, morphology and fractal characteristics of brittle rock fragmentations by the impact loading effect," Acta Mechanica, vol. 226, no. 11, pp. 3623-3637, 2015.

[12] H. Q. Duan and S. Zhang, "Fractal characteristics of coal specimens' surface cracks in triaxial conventional compression and cyclic loading tests," Geotechnical and Geological Engineering, vol. 38, no. 1, pp. 19-29, 2020. 
[13] F. Yang, Z. F. Ning, and H. Q. Liu, "Fractal characteristics of shales from a shale gas reservoir in the Sichuan Basin, China," Fuel, vol. 115, pp. 378-384, 2014.

[14] T. J. Miao, B. M. Yu, Y. G. Duan, and Q. T. Fang, "A fractal analysis of permeability for fractured rocks," International Journal of Heat and Mass Transfer, vol. 81, pp. 75-80, 2015.

[15] B. Z. Tian, S. J. Liu, Y. B. Zhang, and Z. L. Wang, "Analysis of fractal characteristics of fragments form rock burst tests under different loading rates," Technical Gazette, vol. 23, no. 5, pp. 1269-1276, 2016.

[16] S. Q. Xiao, Z. L. Ge, Y. Y. Lu, Z. Zhou, Q. Li, and L. Wang, "Investigation on coal fragmentation by high-velocity water jet in drilling: size distributions and fractal characteristics," Applied Sciences, vol. 8, no. 10, p. 1988, 2018.

[17] R. Yang, D. P. Ma, and Y. J. Yang, "Experimental investigation of energy evolution in sandstone failure during triaxial unloading confining pressure tests," Advances in Civil Engineering, vol. 2019, Article ID 7419752, 11 pages, 2019.

[18] Z. L. Zhou, X. B. Li, Y. J. Zuo, and H. Liang, "Fractal characteristics of rock fragmentation at strain rate of $10^{0}-10^{2} \mathrm{~s}^{-1}$," Journal of Central South University of Technology, vol. 13, no. 3, pp. 290-294, 2006.

[19] D. X. Li, E. Y. Wang, X. G. Kong et al., "Fractal characteristics of acoustic emissions from coal under multi-stage true-triaxial compression," Journal of Geophysics and Engineering, vol. 15, pp. 2021-2032, 2018.

[20] Y. Y. Li, S. C. Zhang, and X. Zhang, "Classification and fractal characteristics of coal rock fragments under uniaxial cyclic loading conditions," Arabian Journal of Geosciences, vol. 11, no. 9, p. 201, 2018.

[21] Y. Y. Xia, M. Q. Lin, L. L. Liao, W. Xiong, and Z. D. Wang, "Fractal characteristic analysis of fragments from rockburst tests of large-diameter specimens," Chinese Journal of Rock Mechanics and Engineering, vol. 33, pp. 1358-1365, 2014.

[22] T. F. Wong, R. H. C. Wong, K. T. Chau, and C. A. Tang, "Microcrack statistics, Weibull distribution and micromechanical modeling of compressive failure in rock," $\mathrm{Me}$ chanics of Materials, vol. 38, no. 7, pp. 664-681, 2006.

[23] S. Ning, Y. Yang, J. Lv, and H. Duan, "The fractal characteristics of coal sample's fragments subjected to cyclic loading," Geotechnical and Geological Engineering, vol. 37, no. 3, pp. 2267-2281, 2019. 